Supporting Information for

\title{
Facile Synthesis of BiCuOS by Hydrothermal Methods
}

William C. Sheets, Evan S. Stampler, Houria Kabbour, Mariana I. Bertoni, Laurent Cario, Thomas O. Mason, Tobin J. Marks, and Kenneth R. Poeppelmeier

Department of Chemistry, Northwestern University, Evanston, IL 60208-3113. 
Figure S1. EDX spectrum of the $\mathrm{BiCuOS}$ shows the presence of $\mathrm{Bi}, \mathrm{Cu}, \mathrm{O}$, and $\mathrm{S}$. The large $\mathrm{Si}$ peak corresponds to the silicon wafer on which the $\mathrm{BiCuOS}$ sample was dispersed.

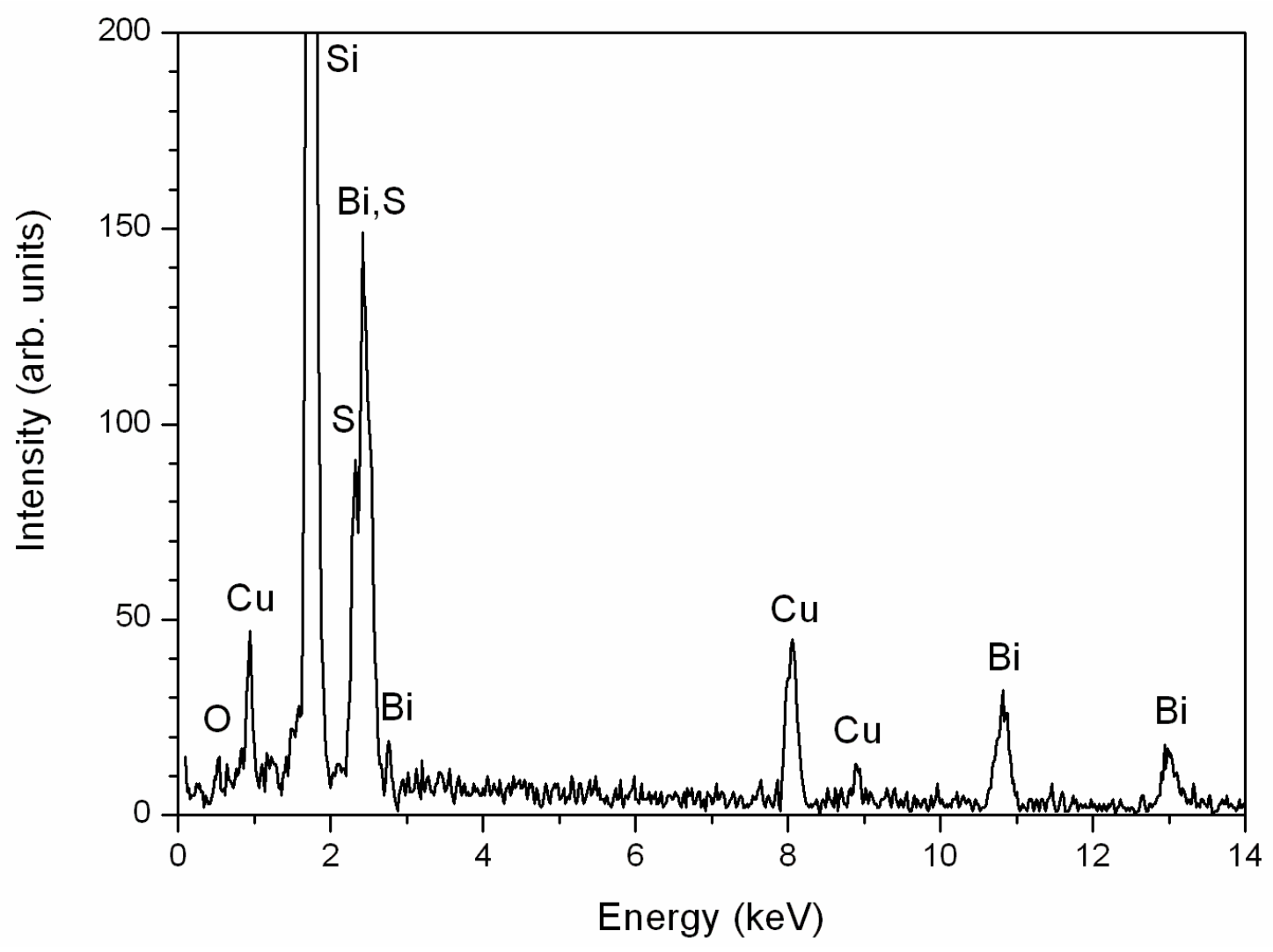

